\title{
Incidental Small Renal Tumor: More Biopsy, Less Surgery?
}

\author{
Martin Spoendlin ${ }^{1}$ and Gernot Bonkat ${ }^{1,2}$
}

${ }^{1}$ Merian Iselin Klinik, Basel, Switzerland

${ }^{2}$ alta uro AG, Basel, Switzerland

In primary care, due to better and more frequently used imaging, medical doctors are increasingly confronted with the challenge of incidental findings of unclear etiology and unknown malignant potential. This leads to the challenging dilemma of deciding between possible overdiagnosis and overtreatment versus the risk of missing a malignancy with the consecutive necessary and beneficial treatment.

The paper by Saba et al. [1] in this issue addresses the problem of overdiagnosis and overtreatment in small renal tumors detected by imaging. Renal tumors $\leq 4 \mathrm{~cm}$ are usually referred to as 'small renal masses' (SRM). Saba et al. retrospectively analyzed all resections of renal tumors suspected of malignancy on CT or MRI from the University Hospital Zurich between 2006 and 2014 with respect to their size on cross-sectional imaging as well as to their definitive histology. Of 404 resected specimens, 221 $(54.7 \%)$ had a tumor diameter $\leq 4 \mathrm{~cm}$. Among these 221 SRM, $28 \%$ were benign lesions and $70.6 \%$ were malignancies (remainder uncertain or low malignancy potential). Of the malignant tumors, $74.4 \%$ had a relatively favorable prognosis based on histology and $25.6 \%$ had an unfavorable prognosis. These figures are similar to those of other published series.

Tumor biopsies are not usually a routine part of the workup for SRM, in contrast to most other tumor types. Saba et al. suggest that the role of tumor kidney biopsy in SRM should be reconsidered in future treatment decisions. The authors state that the biopsy of SRM nowadays has a reasonably low complication rate and a relevant diagnostic value. Furthermore, they state that one of the feared major complications, namely port site metastasis, is exceptionally rare and, if it occurs, should be classified as of nondetermined clinical relevance. In contrast, more distressing complications due to surgery, usually a partial nephrectomy, can occur with a rate as high as $5.5 \%$.

One of the main messages of the paper by Saba et al. is that biopsies of SRM can help reduce surgical overtreatment in elderly and comorbid patients with limited life expectancy who have a prognostically favorable malignancy. They suggest that monitoring these patients with 'active surveillance' might be preferable. They emphasize that this requires dedicated interdisciplinarity and critical questioning of the histology referred to the situation of the patient. Detailed guidelines on this behalf have been elaborated by various professional societies [2-6].
As Saba et al. point out, biopsy of SRM may also help spare from surgery younger and otherwise healthy patients with a benign biopsy histology. The guidelines [2-6] also address the approach to biopsies with benign histology. The accuracy of biopsies compared with histologic diagnoses of surgical specimens should be critically appraised. In a meta-analysis that included series with tumors larger than $4 \mathrm{~cm}$, sensitivity and specificity of biopsies (excluding FNPs) with respect to detection of malignancy were good, but not quite $100 \%$ in the 17 series that examined this issue. Ten out of these 17 studies found sensitivities of $100 \%$, the seven remaining papers described sensitivities that were somewhat lower. The lowest sensitivity was $88 \%$. Only three of these 17 studies were prospective. In this meta-analysis, the concordance between biopsies including FNPs and surgical specimens with respect to subtype of renal cell carcinoma was 90.3 $\%$ (96 \% for tumors $\leq 4 \mathrm{~cm}$ ). Regarding gradings, concordance was $62.5 \%$ (66.7\% for tumors $\leq 4 \mathrm{~cm})$ when using a four-step grading and $86.5 \%$ when using a twostep grading. FNPs performed worse than biopsies [7].

Another retrospective study shows an accuracy of 97.1 $\%$ in detecting malignancy. However, in this study mainly the patients with malignant histology upon biopsy were operated. Out of 95 patients with benign histology only six underwent surgery. Three of these patients (two oncocytomas and one angiomyolipoma in biopsy) ultimately had renal cell carcinoma based on the histology of the surgical specimen [8].

Most of these data come from retrospective studies. The three prospective series included in the aforementioned meta-analysis showed a sensitivity of biopsies (excluding FNPs) with respect to detecting malignancy of 92, 93, and $95 \%$ [7]. To better assess the sensitivity of biopsies, prospective studies would be needed where all patients with any biopsy histology would need to be operated in order that also all patients with benigne biopsy histology would be outcome appraised. Thus, it might be beneficial to include tumor kidney biopsy in the treatment decisions, but we must still be aware that a 'benign tumor biopsy' does not reliably exclude malignancy.

This latter point is particularly important in oncocytomas, the most common benign renal tumors. Typically, hybrid tumors with portions of renal cell carcinoma that might be missed in biopsy occur in oncocytomas [9-11]. The frequency of hybrid tumors in sporadic oncocytomas 
has been reported to be $4.2 \%$ in one series [11] and $6.3 \%$ in unspecified oncocytomas in another [12]. Hybrid tumors are more common in hereditary oncocytoma variants than in sporadic ones [10]. Coexistence of oncocytomas and renal cell carcinomas in the same patient have been described to range from 10 to $32 \%$ [13]. Further, as stated in the paper by Saba et al., the differentiation between a benign oncocytoma and a chromophobe renal cell carcinoma can be challenging for the pathologist. In a meta-analysis based on the surgical specimen oncocytic tumors diagnosed by biopsy were true oncocytomas in only $64.6 \%, 4.2 \%$ were other benign lesions, $25 \%$ were renal cell carcinomas, and $6.3 \%$ were hybrid tumors [12]. Longterm follow-up of unoperated oncocytomas is not available, only some follow-up studies covering up to about three years $[9,10,14,15]$. Therefore, there are critical voices regarding the non-operation of bioptically shown 'benign SRM' and regarding the indication of tumor kidney biopsies in general in patients without limited life expectancy [9]. Close interdisciplinary cooperation between urology, interventional radiology and pathology is absolutely necessary in each individual case when deciding on therapy. The validity of the biopsy histology and radiographic imaging must be critically analyzed and questioned in order to prevent a worse prognosis due to non-surgery because a malignancy was not detected in the biopsy.

The same applies in principle to angiomyolipomas, the second most common benign renal tumors, although imaging has a higher diagnostic accuracy for its fatty form. There are fewer data on the accuracy of biopsies with respect to the diagnosis of angiomyolipoma and differentiation from malignancies than for oncocytomas [16-22].

The work of Saba et al. provides relevant and valuable information for primary care. It is helpful to know that elderly and comorbid patients with limited life expectancy and incidentally discovered, prognostically favorable malignant SRM can be saved from intervention when one takes a biopsy of the tumor in advance of a potential operation. Active surveillance can prevent complications, eventual deterioration of renal function and inconvenience due to surgery. It is of course important that the decision about a therapy is made individually, based on the overall situation in a dialogue between patient, urologist, family doctor and pathologist, taking into account current guidelines. In addition to tumor characteristics, tumor size, and the effectiveness and complication potential of the various treatment modalities, age, life expectancy, comorbidities and renal function, among other factors, must be taken into account. The limited accuracy of biopsy with respect to tumor subtype and grading and consequently with respect to assessing whether the malignancy has a favorable prognosis, must be carefully considered $[7,23]$. The impact of tumor kidney biopsy with benign histology on the treatment decision in patients with non-restricted life expectancy must be critically questioned in each individual case. If surgery is not performed immediately, active surveillance is indicated.

\section{Bibliography}

1. Saba K, Högger DC, Hötker AM, Rupp NJ, Sulser T, Hermanns T. Dignität kleiner Nierentumoren: Implikationen zur Abklärung und Therapie. Praxis. 2021;110:565-570.

2. Wilcox Vanden Berg RN, Basourakos SP, LaRussa S, McClure TD. Management of the small renal mass: a 2020 Update. Curr Oncol Rep. 2020;22(7):69.

3. Finelli A, Ismaila N, Bro B, et al. Management of small renal masses: American Society of Clinical Oncology Clinical Practice Guideline. J Clin Oncol. 2017;35(6):668-680.

4. Ljungberg B, Albiges L, Abu-Ghanem Y, et al. European Association of Urology Guidelines on renal cell carcinoma: The 2019 Update. Eur Urol. 2019;75(5):799-810.

5. Ljungberg B, Albiges L, Bedke J, et al. EU Guidelines on renal cell carcinoma. European Association of Urology 2021. https:// uroweb.org/wp-content/uploads/EAU-Guidelines-on-RenalCell-Carcinoma-2021.pdf; letzter Zugriff: 27.04.2021

6. Campbell S, Uzzo RG, Allaf ME, et al. Renal mass and localized renal cancer: AUA Guideline. J Urol. 2017;198(3): 520-529.

7. Marconi L, Dabestani S, Lam TB, et al. Systematic review and meta-analysis of diagnostic accuracy of percutaneous renal tumour biopsy. Eur Urol. 2016;69(4):660-673.

8. Jeon HG, Seo SI, Jeong BC, et al. Percutaneous kidney biopsy for a small renal mass: a critical appraisal of results. J Urol. 2016;195(3):568-573.

9. Kutikov A, Smaldone MC, Uzzo RG, Haifler M, Bratslavsky G, Leibovich BC. Renal mass biopsy: always, sometimes, or never? Eur Urol. 2016;70(3):403-6.

10. Shuch B, Amin A, Armstrong AJ, et al. Understanding pathologic variants of renal cell carcinoma: distilling therapeutic opportunities from biologic complexity. Eur Urol. 2015;67(1): 85-97.

11. Ginzburg S, Uzzo R, Al-Saleem T, et al. Coexisting hybrid malignancy in a solitary sporadic solid benign renal mass: implications for treating patients following renal biopsy. J Urol. 2014; 191(2):296-300

12. Patel HD, Druskin SC, Rowe SP, Pierorazio PM, Gorin MA, Allaf ME. Surgical histopathology for suspected oncocytoma on renal mass biopsy: a systematic review and meta-analysis. BJU Int. 2017;119(5):661-666.

13. Abdessater M, Kanbar A, Comperat E, et al. Renal oncocytoma: an algorithm for diagnosis and management. Urology. 2020; 143:173-180.

14. Richard PO, Jewett MA, Bhatt JR, Evans AJ, Timilsina N, Finelli A. Active surveillance for renal neoplasms with oncocytic features is safe. J Urol. 2016;195(3):581-586.

15. Liu S, Lee S, Rashid P, et al. Active surveillance is suitable for intermediate term follow-up of renal oncocytoma diagnosed by percutaneous core biopsy. BJU Int. 2016;118(Suppl 3):30-34.

16. Jinzaki M, Silverman SG, Akita H, Mikami S, Oya M. Diagnosis of renal angiomyolipomas: classic, fat-poor, and epithelioid types. Semin Ultrasound CT MR. 2017;38(1):37-46.

17. Jinzaki M, Silverman SG, Akita H, Nagashima Y, Mikami S, Oya M. Renal angiomyolipoma: a radiological classification and update on recent developments in diagnosis and management. Abdom Imaging. 2014;39(3):588-604.

18. Allgood E, Raman SS. Image interpretation: practical triage of benign from malignant renal masses. Radiol Clin North Am. 2020;58(5):875-884.

19. Nicolau C, Antunes N, Paño B, Sebastia C. Imaging characterization of renal masses. Medicina (Kaunas). 2021;8;57(1):51.

20. Kiefer RM, Stavropoulos SW. The role of interventional radiology techniques in the management of renal angiomyolipomas. Curr Urol Rep. 2017;18(5):36.

21. Herts BR, Silverman SG, Hindman NM, et al. Management of the incidental renal mass on CT: A White Paper of the ACRIncidental Findings Committee. J Am Coll Radiol. 2018; 15(2):264-273. 
22. Park BK. Renal Angiomyolipoma: Radiologic classification and imaging features according to the amount of fat. AJR Am J Roentgenol. 2017;209(4):826-835.

23. Ficarra V, Brunelli M, Novara G, et al. Accuracy of on-bench biopsies in the evaluation of the histological subtype, grade, and necrosis of renal tumours. Pathology. 2011;43(2):149-155.

German version under DOI 10.1024/1661-8157/a003717

\section{PD Dr. med. Gernot Bonkat}

Belegarzt an der Merian Iselin Klinik alta uro AG

Centralbahnplatz 6

4051 Basel

Switzerzland

bonkat@alta-uro.com

\section{Dr. med. Martin Spoendlin}

Nephrologie FMH und Allgemeine Innere Medizin FMH

Merian Iselin Klinik

Föhrenstrasse 2

4054 Basel

Switzerland

martin.spoendlin@merianiselin.ch 